\title{
MACHINE-MADE JUSTICE: SOME IMPLICATIONS
}

\author{
JoSEPH J. SPENGLER*
}

I cannot think it will ever be safe to repose much trust in the moral sense of any machine. Samuel Butler, in Erewhon ch. 23.

Many important considerations ... do not lend themselves easily to mathematical expression.... And hence arises a tendency towards assigning wrong proportions to ... forces; those elements being most emphasized which lend themselves most easily to analytical methods.-Alfred Marshall, Principles of Economics 850 (8th ed. 1920).

This essay has to do with certain implications of the use of computers and other mechanical instruments in the definition and the administration of justice. Justice is conceived in its all-inclusive classical sense of giving to every man his due and thereby contributing to the augmentation of a population's "welfare." Specific references to the attainment of justice under criminal or private law or within the administrative process are intended only to illustrate aspects of the argument; they are not intended to focus the argument upon a certain category of justice or to confine the application of the argument. This essay is prompted by the belief that, even when a great deal of incontrovertible information is present, the judgment and discretion of men of broad humanism must complement the findings of those of a narrower scientific bent; otherwise the art of statecraft is bound to suffer.'

In skeletal form our argument runs as follows. In section one it is contended that any reduction in individual freedom from constraint below the minimum necessary to achieve "justice" and (hence) "welfare" reduces the attainable "welfare" of the population. 2 In section two it is shown how the use of computers and

* A.B. 1926, M.A. I929, Ph.D. 1930, Ohio State University. James B. Duke Professor of Economics, Duke University. Editor and contributor, NAtUral Resources and Economic Growtr (196r); Editor, [with Ralph Braibanti], Administration AND Economic Development in INDia (1963). Contributor to periodicals and symposia dealing with demography, economics, political science, and sociology.

The author is greatly indebted to Professor Ralph Braibanti and to Mr. Walter L. Johnson for suggestions which have improved the content and the presentation of the theme of this essay; he is, of course, solely responsible for its defects.

${ }^{1}$ The importance of the role of value judgment in decision making has been admirably stated by Professor Ralph Braibanti: "The lesser the bureaucratic disposition to reduce the data to incontrovertible, or at least empirically oriented factors, or the lesser the capacity of the data to be so reduced, the greater the dimensions of the value judgment sector. The value environment of decision making has been submitted to only minimal serutiny in studies of bureaucracy, probably because its clusiveness makes it inherently more amenable to philosophic illumination than to empirical analysis.... The expansion of bureaucratic discretion directs attention to the predispositions which mold the values held by men who make the decisions, so that the traditions, ethos, and training of the bureaucrat is of crucial significance, a significance directly proportional to the scope of discretionary power which he possesses." See Braibanti, The Civil Service of Pakistan: A Theoretical Analysis, 58 South Atuantrc Q. 258, 26I (1959).

"On difficulties attending the formulation of adequate indicators of "welfare," see R. DuNCaN * Howard Raiffa, Games and Decisions ch. I4 (I957); William J. Baumor, Economic Theony and OpErations ANALYsIs chs. 13, 17 (1961); also works cited infra note 3. The varicty of meaning assigned to such concepts as liberty and freedom is suggested in the Robert E. Cushman Festschrift, Milton R. Konvitz \& Cinton Rossiter (Eds.), Aspects of Liberty (1958). John P. Roche even suggests that two traditions of liberty have permeated American ideology. Id. at 129.62. 
similar instruments may operate to reduce freedom from constraint below this necessary minimum. In section three we point to developments in the administrative structure of modern states that are likely to accentuate the tendency described in the second section.

I

\section{Freedom from Constraint and Weifare}

The objective of our arrangements respecting the definition and the administration of what we call "justice" is generally assumed to be the augmentation of the "welfare" of the population composing the community. We may define augmentation of welfare in one of several ways. We may say that aggregate welfare is increased by whatever augments the welfare of some without at the same time diminishing that of others. Or we may define welfare in such a way that we may speak of changes in the social welfare function of the people composing our community. For the purposes of my argument either definition of welfare suffices, particularly since the first may be viewed as a special case of the second. I shall, however, usually express myself in terms of the second definition since it is more general as well as better suited to the needs of expositive convenience.

Evaluation of the use of computers and similar instruments in the administration of justice turns in part on the purpose which "justice," viewed as an instrument of "social control," is intended to serve. We may define this purpose as the augmentation of the magnitude of that social welfare function $W$, which the members of a society are endeavoring to maximize. We need not, of course, define the content of this function since that content tends to vary in space as well as in time. We shall take it for granted, however, that the most economical of the available methods of administering justice needs to be chosen when several or more methods appear initially to be equally well suited to increase this social welfare function $W$ by a given amount. For the resultant saving in time and in justice-administering inputs permits a further increase in the value of $W$; and this increase may be significant when courts and personnel are in short supply, court dockets are crowded, and the final disposition of cases tends to lag far behind their emergence. Indeed, the possibility of such savings will become a strong motive for the use of computers, and so on.

For the purposes of this essay, laws and decrees, among them those intended to give rise to "justice," are looked upon as collectively imposed constraints designed to augment the magnitude of the collectivity's social welfare function $W$. These legal instruments, by interdicting certain acts and certain uses of goods and services, make more goods and services available for other uses; they thus may be said (albeit somewhat incorrectly) to perform a creative function in so far as they make the flow of non-interdicted goods and services greater than it otherwise would have been. We shall couch our subsequent discussion in terms of the language of constraints.

Let us include in a universal set $S$ all the behavior of the members of a community which can or does affect, positively or negatively, the social welfare function 
$W$ which the collectivity is bent upon maximizing. Let us suppose, furthermore, that this community's legislature believes correctly that, if $W$ is to be maximized, some but not all of the behavior in $S$ needs to be subjected to a minimum degree of constraint. Let us include in sub-set $S^{\prime}$ all the behavior in need of such constraint and in sub-set $S^{\prime \prime}$ all the behavior not in need of constraint. Finally, let us include in sub-set $C$ all the behavior in $S$ that becomes subject to constraint when all the rules and doctrines designed to carry out the enacted constraining legislation have been put into effect. If these rules and doctrines are so designed and carried out that they just actualize the intent of the legislature, sub-sets $C$ and $S^{\prime}$ will be coterminous and equal in scope. The happy outcome may not be realized, however. The rules and doctrines introduced and employed to administer the enacted legislation may exceed the intent of the legislature; they may provide for more constraint than the minimum required to maximize $W$. If this be the case, $C$ will entrench upon $S^{\prime \prime}$ and exceed $S^{\prime}$ in scope.

When $C$ exceeds $S^{\prime}$, some if not all individuals enjoy less freedom from constraint than the legislature correctly believed was essential to the maximization of $W$. (We are ignoring the case in which the constraints imposed by the legislature are unwittingly excessive, since a fortiori our argument then becomes stronger). In consequence they cannot make as nice adjustments to the parameters of constraint intended by the legislature. Moreover, there can be no costless provision for the adequate compensation of those whom the bureaucrats have deprived of some of the freedom from constraint which the legislature correctly found essential to the maximization of $W$; for this excess constraint has not generated somewhere in the system a surplus of benefits out of which injured individuals might be compensated. The rationale of the argument of this paragraph is easily indicated.

Every individual has an order of choice which reflects his income, his education, the amount of relevant information at his disposal, as well as other of the conditions constituting the matrix of circumstances within which his choosing among alternatives is carried on. Among these conditions is the degree of constraint to which he is subjected by the collectivity through legislation, and so on. The higher the position to which an individual is able to attain on his order of choice, the better off he is. Furthermore, the community of which an individual is a member will also be better off, given that our individual moves only as high on his order of choice as is compatible with no other member of the community having his position on his own order of choice lowered. The situation here described as preferable is not necessarily the best which a community may attain, given some specific social welfare function $W$ to be maximized, since there may be more constraint provided than is required to permit the maximization of $W$. It is adequate, however, to lend support to the type of argument here being advanced. ${ }^{3}$ For the situation envisaged is analogous to that of a "free market" which, while it permits the individual qua individual to choose among alternatives, "does not establish the optimum social

${ }^{3}$ On the economic aspects of welfare, see I. M. D. Litrue, A CRITIQue of Welfare Economics (1957); Jerome Rothenberc, The Measurement of Sociai Wel Whare (196x). 
state in the. sense that individuals, if called upon to vote politically (act collectively) for or against the market-determined state in opposition to a series of alternatives, would consistently choose it."4

Given the matrix of conditions surrounding an individual's acts of choosing among alternatives, he is most likely :to reach the highest position on his order of choice, attainable without worsening any other individual's position, if he is unconstrained and free to move along his order of choice, subject only to the restrictions intended by the legislature. He might; of course, be able to reach a higher position if somehow his education were increased, or more relevant information were put at his disposal, or some other element in his matrix of choice-surrounding conditions were modified. Given this matrix of conditions, however, or (for that matter) any other matrix of conditions, he needs to be free of constraints if he is to attain the most preferred position open to him. Analysis of the behavior even of sometimes irrational economic decision-makers suggests that our individual, if unconstrained, will presumably tend to respond rationally to changes in the matrix of conditions surrounding him even though he sometimes indulges in irrational behavior."

The matrix of conditions surrounding an individual's acts of choosing may be modified, as has been suggested, to include constraints. These constraints may be of the sort which reduce welfare (e.g., governmental support of monopoly pricing), or they may be of a sort which bring about greater consistency between the situation likely to emerge in a society and the situation implicit in that society's social welfare function $W$. In either instance, however, and especially in the latter, freedom of choice is essential if each individual is to be enabled to reach his most preferred position, compatibly with the specified matrix of conditions and with the restriction that no other individual's position is lowered.

The argument advanced has emphasized only the instrumental value of freedom from constraints. As Frank Knight points out, however, freedom, or its possession, may also have absolute value in that a representative individual might prefer a given amount of freedom even if realization of this amount entailed (as is unlikely) a diminution in the welfare (exclusive of freedom) he might otherwise attain. ${ }^{6}$ Such an evaluation of "freedom" seems to have been endorsed also by Lord Acton." It was given psychological support, furthermore, by I. P. Pavlov, when he argued that there exists a special freedom reflex, ${ }^{8}$ and by P. A. Sorokin, when he indicated

\footnotetext{
'See Buchanan, Social Choice, Democracy, and Free Markets, 62 J. PoL. Econ. I22 (1954).

'See Gary S. Becker's interesting essay, Irrational Behavior and Economic Theory, 70 J. Por. Econ. $1-r_{3}(1962)$.

${ }^{\circ}$ See his Freedom and Reform 55-56 (1947); also Free Society: Its Basic Nature and Problems, 57 Philosophical Rev. 49, 5 I (1948).

${ }^{7}$ Sec his Essays on Freedom and Power 51 (Himmelfarb ed. I949).

8 "The freedom reflex is one of the most important reflexes, or, if we use a more general term, reactions, of living beings.... If the animal were not provided with the reflex of protest against boundaries set to its freedom, the smallest obstacle in its path would interfere with the proper fulfilment of its natural functions." See Condrinoned Refrexes 12 (G. V. Anrap transl. 1927), cited in 3 P. A. Sorokin, Social and Cultural. Dynamics 174 (1937).
} 
"a minimum of Sensate liberty" to be essential to the survival of groups as well as of individuals. ${ }^{9}$ We shall, however, rest our argument only upon the instrumental value of freedom from constraint.

In this section we have argued, in effect, that if a community of people wishes to maximize some social welfare function $W$, it may have to impose upon its members some optimal amount $O$ of constraint, and that, given $O$, welfare can then be greatest only if each individual is free to make the best adjustment he can to his environment and his fellows within the boundary fixed by constraint $O$. This possibility tended to materialize when sub-set $C$ approximated $S^{\prime}$, and it receded as $C$ tended to exceed $S^{\prime}$ and carry constraint beyond $O$. In the next section we shall argue that the use of computers in the definition and administration of justice can easily cause $C$ to exceed $S^{\prime}$ and thus augment constraint above the optimum level $O$ and thereby diminish the magnitude of $W$.

\section{II}

\section{Conceptual Rigidity and Bias}

The function of conceptual structures is to illuminate that part of reality to which they supposedly relate and perhaps to increase man's ability to adjust to this part of reality or otherwise cope with it. Underlying reality is characterized by continuity and by great propensity to variation (if only in minor particulars over shorter periods of time). Superficially at least, any one of a vast number of conceptual structures may appear compatible with some portion of reality. In the end, however, one or several may be quite superior, on some principle such as Occam's razor, to the others, at least in the sense of affording an explanation of that portion of reality to which they relate. This appearance of compatibility is fostered, of course, by the fact that no conceptual or theoretical structure deals with reality as such; it merely abstracts from reality and so in effect deals with supposed indicators of reality. ${ }^{\mathbf{1 0}}$

The conceptual structure employed by a scientist helps to determine what he "sees", how he interprets it, and, if he is an administrator, how he tends to apply what he thinks he sees. Thus this structure sharpens and directs his focus, albeit conceivably upon relatively less significant portions of reality, given the intent of his inquiry. Recourse to one rather than to some other theoretical or conceptual structure imposes an opportunity cost on its user, at least for the time being; it denies to him the opportunity to have recourse to other conceptual structures. This cost may, of course, be of negligible significance if the conceptual structure chosen is the one best suited to facilitate the inquiry in question and solve the problem prompting this inquiry. It may be of great significance, however, if the conceptual structure chosen directs inquiry along relatively unfruitful lines.

We may turn for purposes of illustration to the Whorfian hypothesis that the

Id. at $173-75$.

${ }^{10}$ See my Theory, Ideology, Non-Economic Values, and Politica-Economic Development, in Ratpit Braibanti \& Joseph J. Spengler (Eds.), Traditton, Values, and Socto-Economic Development 12 (I96r). 
structure of a people's language determines the "world view" of their culture. Among the implications of this hypothesis is the view that each language tends to facilitate some kinds of expression and inquiry, and to hinder others. Categorization, and so on, are affected accordingly. For, as J. A. Fishman remarks, "What is easily codifiable, and the specific range and content of easily codeable categories, does depend on the particular language under consideration."11 And, as R. D. Gastil observes, if a man thinking or expressing himself in a given language does not, because that language lacks certain words and forms, "have the means to do a certain job of thinking or expressing, that job will not be accomplished as well as if he had such means." ${ }^{2}$ This type of handicap was experienced by Galileo when, in his inquiry into uniformly accelerated motion, he underestimated the role of the time factor. He lacked the necessary idiom and the theory of fluxions which Newton was to develop; and so the "time factor" was slow to receive due weight in the representations of reality employed. N. R. Hanson points to the underlying reason: $:^{13}$

But it is understandable why this factor should so long have been overlooked: thinking new thoughts in a conceptual framework not designed to express them requires unprecedented physical insights. In the history of physics few could sense the importance of things not yet expressible in current idioms. The task of the few has been to find means of saying what is for others unsayable.

The obverse of this sort of explanation is that, as the Whorfian hypothesis suggests, if there is ready to hand a collection of verbal symbols seemingly suited to express what they are not really suited to say, that which is observed is. likely to be compressed into these symbols and thereby distorted, particularly if these symbols are limited in number as well as in applicability to the task of expressing the observed. ${ }^{14}$

In as much as unique factors and unique combinations of possible circumstances are among the elements constituting specific cases, uniqueness is present in nearly every case that arises for consideration and study, or calls for solution, and must be taken into account if a satisfactory solution is to be forthcoming. Uniqueness is a less important source of concern, of course, at the level of explanation than at the level of application where neglect of uniqueness, owing to conceptual inflexibility, may significantly distort findings. At the level of explanation it usually is possible to abstract from some if not from all of the uniqueness associated with individual cases or instances. For example, if we are isolating for purposes of explanation the attributes of actions which render them illegal we look to such general characteristics as legality,

${ }^{21}$ See Fishman, A Systematization of the Whorfian Hypothesis, 5 Benavioral Science 323, 330 (1960). On B. L. Whorf's theory, see also Radnitzky, Some Remaxks on the Whorfian Hypothesis, 6 id. 153-57 (196r), and Roger Brown, WORDs AND Thungs ch. 7 (1959).

12 Cited by Fishman, supra note 11, at 328-29.

${ }^{18}$ N. R. Hanson, Patterns of Discovery 46 (1958).

14 See Ernst Casstrer, Language and Mrty esp. ch. 3 (Langer transl. 1945). See also Newman, The Patterns of Vowels and Consonants in Various Languages, 64 AMr. Psychological Rev. 369 (195r). Newman finds largeness of a people's vocabulary to be associated with the complexity of its culture and cultural history. 
conduct, harm, concurrence of conduct and harm, mens rea, causation, and so on. But when we are seeking to determine if some specific action is criminal, together with the guilt (if any) of its alleged perpetrator, we must ascertain if the rules defining and distinguishing particular crimes identify the specific action in question to be a criminal one, and if doctrines (e.g., of insanity, coercion, and so on) which fix certain aspects of crime in general define the specific action in question to have been performed in such a way as to meet these more general requirements of crime. ${ }^{15}$ At the level of application-in the present example, at the concrete level at which criminal justice is administered-generality is limited, uniqueness is important, and many more or less concrete elements must be taken into account. For this reason the conceptual structure employed must be applied quite flexibly.

A digital computer has been defined as "a general-purpose symbol-manipulating device. -If appropriate programs are written for it, it can be made to produce symbolic output that can be compared with the stream of verbalizations of a human being who is thinking aloud while solving problems." ${ }^{10}$ It handles a small amount of information very rapidly (sometimes indeed with potentially dangerous rapidity) whereas the human nervous. system handles many items of information simultaneously though much more slowly. ${ }^{17}$ "It promises," Leonard Uhr optimistically believes, "within the next ten years, to actually achieve-in potential-all the powers of the human brain."18 Even so, the kinds of inquiries, the kinds of information storage and retrieval, and the kinds of multivariate analysis of which a computer seems capable in respect of -the determination of justice appear to be limited; certainly more limited than those of which the human brain is capable in the aggregate. For the world of justice is very complex, especially when translated into terms of individual cases requiring adjudication rather than in terms of a genus of cases requiring only general discussion. What Clarkson and Simon observe in another connection seems pertinent therefore in the present connection: $:^{10}$

The real world is still orders of magnitude more complex than the simulations we can handle on present or prospective computers. We still need to think, and think hard, about what part of reality needs to be incorporated in the model if it is to provide reasonable answers to the questions we wish to ask of it.

This complexity of the real world, be it in the realm of justice or elsewhere, may therefore cause use of computers to make for imperfect analysis and for bias in the interpretation of results, especially in the realm of justice, as well as for

\footnotetext{
${ }^{15}$ See Hall, Some Basic Questions Regarding Legal Classification for Professional and Scientific Purposes, 5 J. LeGal ED. 338 (1953).

${ }^{10}$ Newell \& Simon, Computer Simulation of Human Thinking, 134 ScIEnce 2016 (1961). Sce also Clarkson \& Simon, Simulation of Individual and Group Behavior, 50 AM. EcoN. REv. 920, 924-25 (I960).

${ }^{17}$ See S. Ulam's review of John von Neumann, The Computer and the Brain, Scientific American, June 1958, pp. x27, 128. See also Neisser, The Imitation of Man by Machine, 139 Science 193, 196-97 $(1963)$.

${ }^{18} \mathrm{Uhr}$, Intelligence in Computers: The Psychology of Perception in People and in Machines, 5 Behavioral Science 178 (1960). But for differences between man and machine, sec Neisser, supra note 17.

${ }^{10}$ Clarkson \& Simon, stupra note 16 , at 930.
} 
misapplication of the findings of imperfect analysis. Problems in this realm are likely to be of the sort that are poorly adapted to computer solution or simulation; they are likely to be essentially non-routine in character and to involve inputs, outputs, programs, and parameters (e.g., values) which are not very measurable and which are hard (if not impossible) to define finitely and with necessary precision. If analysts seek to escape these shortcomings by treating elements of a problem as independent, routine elements when in fact these elements constitute a kind of meaning-giving gestalt, they will misinterpret the significance of these elements, and they will accentuate this misinterpretation if they also neglect (as they are likely to do) matter which is recalcitrant to routinization and decomposition into simple elements. If application is not made of such imperfect findings, only limited harm results, namely, deceleration of the rate of growth of knowledge. If, however, these findings are applied, much greater harm can result. Even so, the disposition to apply such imperfect and misleading findings will be great. There will always be the pressure of economy, to save time and factor inputs, especially when these are in quite short supply. There will also be the even greater pressure of man's inclination to accept seemingly concrete answers and to avoid responsibility for hard decisions, especially when escape from such pressure appears to be found in computer-based answers and decisions. The computer is thus easily converted into an anxiety-relieving deus ex machina, whose utterances are susceptible of being interpreted as those of Allah. Whence Johnson and Kohler warn us not to turn over to the computer responsibilities with which man is better able to cope: $:^{20}$

It is being called on to act for man in areas where man cannot define his own ability to perform and where he feels uneasy about his own performance-where he would like a neat, well-structured solution and feels that in adopting the machine's partial solution he is closer to the "right" than he is in using his own. An aura of respectability surrounds a computer output, and this, together with the time-balance factor, makes unqualified acceptance tempting.

This warning is confirmed by Neisser $:^{21}$

If machines really thought as men do, there would be no more reason to fear them than to fear men. But computer intelligence is indeed "inhuman": it does not grow, has no emotional basis, and is shallowly motivated. These defects do not matter in technical applications, where the criteria of successful problem solving are relatively simple. They become extremely important if the computer is used to make social decisions, for there our criteria of adequacy are as subtle and as multiply motivated as human thinking itself.

Perhaps relevant also is Norbert Wiener's conclusion that the "human brain is a far more effective control apparatus than is the intelligent machine when we come to higher areas of logic" and (his analysis implies) policy. ${ }^{22}$

Further elaboration of the dangers attending computer use, to which attention

${ }^{20}$ Johnson \& Kohler, The Man-Computer Relationship, I38 Scrence 879 (r962).

21 Neisser, supra note I7, at 197 .

${ }^{22}$ Wiener, Some Moral and Technical Consequences of Automation, 131 SarNce 1357 (1960). 
has been drawn in the preceding paragraphs, is unnecessary at this stage of our argument. It is now in order, however, to draw attention to a problem of major importance in the realm of justice and one which incorporates in itself some of the difficulties already noted. The administration of justice can contribute most effectively to the augmentation of individual and total welfare when it is flexible, adapted to the uniqueness of cases and to variability and change in circumstances, and is carried out subject to no more constraint than the minimum essential to the accomplishment of the purported aim of the legislation on which rests the administration of justice in concrete instances. Optimal administration of justice therefore entails non-rigidity in the conceptual structure on which it is based, particularly at the level of application. Yet, as will be shown, the introduction of computers and similar instruments can easily be accompanied by rigidification of the legal and related conceptual structure.

Conceptual rigidity tends to arise if the concepts used and the information available for the definition and administration of justice are only partially adapted to the requirements of computer programming. Table one has been devised to illustrate this point. In the first column, $C_{\mathrm{c}}$ designates the concepts adapted to computer programming, and $C_{\mathrm{r}}$, the concepts not currently suited thereto. $C$ is the

\section{TABLE I}

\begin{tabular}{|c|c|c|}
\hline \multirow{3}{*}{ Concepts } & \multicolumn{2}{|c|}{ Information } \\
\cline { 2 - 3 } & Required & Available \\
\hline$C_{\mathrm{o}}$ & $I_{\mathrm{o}}$ & $I_{\mathrm{a}_{\mathrm{o}}}$ \\
$C_{\mathrm{z}}$ & $I_{\mathrm{s}}$ & $I_{\mathrm{a}_{\mathrm{s}}}$ \\
$C=C_{\mathrm{o}}+C_{\mathrm{r}}$ & $I=I_{\mathrm{o}}+I_{\mathrm{s}}$ & $I_{\mathrm{a}}=I_{\mathrm{a}}+I_{\mathrm{a}_{s}}$ \\
\hline
\end{tabular}

set of concepts including both $C_{\mathrm{c}}$ and $C_{\mathrm{r}}$; presumably all concepts included in this set are adapted to non-computer use even though $C_{c}$ is sequestered because of its adaptability to computer use. In the second column, $I_{c}$ designates that kind of information which is both required in representative cases and is adapted to computer manipulation. Since $I$ denotes all the information required for the satisfactory determination of such cases, $I_{\boldsymbol{r}}$ designates the required residuum of information not adaptable to computer manipulation though susceptible of manipulation in other ways. $I_{\mathfrak{a}}$ in the third column denotes all the relevant information actually in existence and accessible; it is subdivided into $I_{a}$, information both actually or potentially available and adaptable to computer use, and $I_{a_{r}}$, other information actually or potentially available though not adapted to computer use. It is evident that if $L_{a_{0}}$ approximates $I$, the cases in question can be readily handled. Furthermore, they can be handled through partial use of computers if also $I_{\mathrm{a}_{\mathrm{c}}}$ approximates $I_{\mathrm{c}}$ in keeping with concepts $C_{c}$. Difficulties may arise, however, if $I_{a_{0}}$ falls quite short of $I_{c}$ even when $I_{a_{z}}$ approximates $I_{t}$. To these difficulties we may now turn. 
In a legal world wholly adapted to the requirements of computer programming, all the concepts employed would be of the category $C_{\mathrm{c}}$ sort, and $I_{\mathrm{a}}$, the information actually or potentially available, would approximate both $I_{\mathrm{a}_{\mathrm{c}}}$ and $I_{\mathrm{c}}$. There would be no need for the use of concepts $C_{\mathrm{r}}$ or for information $I_{\mathrm{r}}$. These computeroriented conditions are unlikely to be met, however, at least for a long time. Many utilized concepts (as well as both required and accessible information) answer to the categorical descriptions appearing on the second line in the body of table one. Accordingly, those bent on augmenting the use of computers, and so on, in the administration of justice-and their number may be large, given the economies that computers make possible and the clogged condition of most court dockets-will try to convert $C_{\mathrm{r}}$ into $C_{\mathrm{c}}$ concepts and thus increase the importance of required information $I_{c}$ at the expense of required information $I_{r}$. If such conversion is not possible on a sufficient scale, efforts will probably be made to depreciate the relative importance of $C_{\mathbf{r}}$ concepts and increase that of $C_{\mathbf{c}}$ concepts. Suppose that such conversion, or such revaluation, is carried out and that the relative importance of $C_{x}$ and $I_{r}$ is greatly reduced. It may still happen that most of the information actually or potentially available is of the $I_{\mathrm{a}_{\mathrm{r}}}$ sort and that not much corresponds to to $I_{a_{c}}$ and thus to $I_{\mathrm{c}}$ specifications. Again there will be need either somehow to convert $I_{a_{r}}$ information into $I_{a_{c}}$ information, or to depreciate greatly the role of $I_{\mathrm{a}_{\mathrm{r}}}$ information and appreciate that of $I_{\mathrm{a}_{\mathrm{c}}}$ information.

What will be the upshot of these efforts at conversion and re-evaluation of concepts and information? That depends upon how fixed and non-extensible categories $C_{c}$, $I_{c}$, and $I_{a_{c}}$ are. In proportion as they are fixed and non-extensible because of technological limitations upon the improvement of computers and of economic and other limitations upon the kind of computer-oriented information actually to be had, efforts will probably be made to redefine rules of evidence, such as relevance, kinds of evidence required, and so on. In other words, efforts will be made to gear the concept-structure in use to the dimensions of $C_{c}$ and thereby to increase the relative importance of $I_{\mathrm{c}}$. Then, given ex hypothesi that category $C_{\mathrm{c}}$ is relatively fixed, the dominant conceptual structure will be relatively fixed. Even though the world to which the rules of law and justice are to be applied will be changing and hence in need of frequent change in that part of its conceptual structure which relates to law and justice, such needed change will be slow in coming and too small in amount when it does come. The resulting juristic conceptual structure, lacking the dynamism of the economy and polity to which it relates, may become even more maladjusted to this economy and polity than at present. For a conceptual structure, be it juristic or otherwise, must, if it is to be of maximum usefulness, remain flexible, much as an efficient language remains flexible and changes in consonance with changing circumstances. Plato recognized this more than 2,000 years ago when in the Statesman he had the Eleatic Stranger say:23

${ }^{38} 2$ The Dialogues of Plato 322 (B. Jowett transl. 1937). 
...the law does not perfectly comprehend what is noblest and most just for all and therefore cannot enforce what is best. The differences of men and actions, and the endless irregular movements of human beings, do not admit of any universal and simple rule. And no art whatsoever can lay down a rule which will last for all time.

In this section we have shown how the introduction of the use of computer and similar mechanical instruments into the administration of justice may prove unfavorable thereto and may thus tend to reduce the level of aggregate welfare as reflected in a social welfare function $W$ such as was described in the preceding section. Computer use will do this in so far as it makes for imperfect analysis, for misinterpretation of results, for bias in the application of findings, for avoidance of responsibility for hard decisions, for conceptual rigidity, and for greater constraint upon individual freedom than maximization of $W$ requires. Computer use is more likely to produce such effects in the very heterogeneous realm of justice than in other relatively homogeneous realms, because in the former realm the primary concern of most inquiries is the individual concrete instance or case, and not a somewhat abstract and idealized (or conceptualized) instance that answers roughly to the description of something that can be simulated or resolved through computer methods. Thus many of the difficulties attendant upon computer use in the administration of justice inhere in the problems involved rather than in the failure of analysts to correct remediable shortcomings in the adjustment of computer methods to the administration of justice. Problems of the latter sort can be overcome whereas those of the former sort are likely to persist. One cannot, therefore, infer that because case and code law have been somewhat adjusted to each other, a comparable adjustment of the requirements of ideal justice to the abilities of an ideal computer is to be expected. 'The gap is reducible but not removable. The actual impact of the use of computers in the administration of justice will be conditioned, of course, by a country's legal structure and by the manner in which the apparatus of state is employed. It is to this impact that we now turn in section three.

III

\section{COMPUTER IMPACT UPON JUSTICE IN THE REAL WORDD}

The impact of the use of computers in the administration of justice is conditioned largely by the extent of the regulatory role performed by the state, by the legal and administrative structure employed, by the degree to which arbitrary use of power is uncircumscribed, and by the capacity of private persons to arm themselves against the use of computer-based information and analysis. Let us, therefore, examine some of these conditions.

Of these conditions two are of especial importance, the extent of the role of the state and the degree to which this role expresses the tastes and desires of the whole population. In a nation in which the role of the state is small and justiciable matters are largely resolved without state intervention, the computer could never play more than a negligible part. Today, as a rule, however, the role of the state is very great, 
and this role tends to be reinforced by prevailing public opinion, this opinion having changed greatly since Marx's day when even his followers looked upon the current state as an oppressive institution and when many non-Marxists shared Herbert Spencer's belief that the function of "true liberalism" had become "that of putting a limit to the powers of Parliaments" and to the growth of officials and officialism. ${ }^{24}$ Yet even today, though the role of the state is extensive, it reflects in widely varying degree the wishes of the whole population. Indeed, national societies are roughly of three sorts, the "democratic," the state-dominated, and (at least in theory) those falling between these polar categories. In an essentially democratic society the state is the governing agency of that society and remains very subject to democratic or popular indications respecting "who shall govern and to what ends"; 25 the social welfare function sought through the apparatus of state tends to reflect that of the whole population. By contrast, in a state-dominated society, typified by those of present-day "communist" nations, the state has largely swamped the society from which it emerged; the social welfare function sought is defined and implemented mainly by the ruling circles, and in but partially restrained independence of the social welfare function of the underlying population. ${ }^{26}$

In view of what has been said the argument developed in section two is not likely to be accorded much weight in a state-dominated, or "communist" type of state, though disregard of the dangers there noted would tend to reduce the extent to which the avowed objectives of such a state could be reached. This argument is of great pertinence, however, in the modern "welfare" or social-service state, though the degree of this pertinence will be conditiond by the extent to which the judicial process makes for the selection of those rules which respect "the facts of men's social existence and... promote an effective and satisfactory life in common."27

Such an outcome tends to be favored more by the case-law approach associated: with the common law than by code law. ${ }^{28}$ For, as $\mathrm{M}$. Polanyi has pointed out, this approach exemplifies a system of spontaneous order whereunder coordination is brought about largely through mutual adjustment and readjustment on the part of individuals exercising private initiative. "The operation of Common Law thus constitutes a sequence of adjustments between succeeding judges, guided by a parallel interaction between the judges and the general public."29 The underlying

"Sec Herbert Spencer, The Man Versus the State 28, yo7 (I884).

${ }^{25}$ See R. M. MAcIver, The Web of Government 193, 196-98 (1947). Within the "community," a delimited area of that web of relationships called society, "are generated many controls that are not governmental controls, many associations that are not political associations, many usages and standards of behavior that are in no sense the creation of the state. In the community develops the law behind the law, the multi-sanctioned law that existed before governments began and that the law of governments can never supersede." Id. at 193. (1962).

${ }^{30}$ See, e.g., Downs, The Public Interest: Its Meaning in a Democracy, 29 Social Research I-36

${ }^{27}$ Fuller, Reason and Fiat in Case Law, 59 Harv. L. Rev. 381 (1946).

${ }^{28}$ See id. at 392, for what appears to be Fuller's endorsement of this view. But see his comments on legal realism in American Legal Realism, in 76 Proceedisgs of The American Philosophicai SOCIETY rgr (1936).

2* M. Polanyi, The Logic of Liberty 159-162 (195I). 
method and approach are essentially experimental rather than deductive as under the code approach.

The historic "common law" of Anglo-American jurisprudence is only a special case of the universal principle common to all concerns that survive, of making new law by deciding conflicts of interest, thus giving greater precision and organized compulsion to the unorganized working rules of custom or ethics. ${ }^{30}$

Presumably, in so far as custom sanctions such an experimental and flexible approach, the tendency will be strong for necessary readjustment to be accomplished with minimum positive action on the part of the state much as price and cost readjustments are accomplished within the realm of the market under the pressure of "competition" rather than under that of state fiat. Indeed, this tendency, an indirect concomitant of the experimental approach of common law, probably contributes far more to the augmentation of welfare than do the direct accomplishments of the common-law approach.

A piece-meal, essentially backward-looking approach may not, however, be able to keep pace with supposed needs in times of dynamic change. The resulting lag, together with the desire to retain as much flexibility as practicable, has given rise to legislation in many areas (e.g., labor relations, transport, commerce, taxation, and so on) and to the devolution of related regulatory and judicial power to independent administrative agencies. For one reason or another, however, the hoped-for celerity and flexibility have not been realized; and there has been much complaint of undue arbitrariness and non-uniformity (where uniformity is indicated).

Three decades ago already the Lord Chief Justice of England was warning of "the new despotism" implicit in the substitution of "administrative law" for the "rule of law" and the associated increase in "the pretensions and encroachments of bureaucracy." United States where complaint at unchecked administrative rule-making power gave rise in 1946 to the Administrative Procedure Act, an act designed to guard the rights of private litigants against government agencies. ${ }^{32}$ Even so, it may prove difficult to secure effective judicial review. It may also prove difficult to resist harassment by administrative agencies, whether initiated by a Leviathan executive branch of the government against objects of its wrath, or by "little men" with "big" authority and misunderstandings or animus of one sort or another. ${ }^{33}$

Those subject to regulatory agencies may find themselves objects of prejudice.

${ }^{30}$ See John R. Commons, Institutional Economics 73, 72-74, 22I, 239-40 (1934).

${ }^{31}$ Lord Hewart of Bury, The New Despotism chs. I-3 (I929).

${ }^{32}$ Complaint at the progressive exemption of administrative agencies from judicial revicw was effectively expressed by Roscoe Pound, among others. See Roscoe Pound, Administrative Agencies and the Law (American Affairs Pamphlets, r946). See also Frank E. Coopen, Administtutive AGENCIES AND THE CourTs (195x); Bookman, Regulation by Elephant, Rabbit, and Lark, Fortunc, June $x 96 \mathrm{r}$, p. $137 \mathrm{ff}$.

${ }^{83}$ Kristol, Big Government and Little Men, New Leader, Nov. 26, 1962, p. 13. Fortune warns in an editorial that the "discretionary scope of federal officials is now so wide that they can arbitrarily grant or withhold prosperity from most of the larger businesses now operating in the U. S.- and ... without violating the law." Whence "white corruption" tends to emerge. Fortune, Feb. 1963, p. 82. 
It has, for instance, been suggested by a critic of the welfare state, Professor Sylvester Petro, that some recent actions based upon the Sherman Act and related legislation reflect "a suspicion of free enterprise and genuine free competition" and suggest that action is likely to be directed against business by an administration "inimical to the values of free enterprise."34 Against the infringement of individual rights and the wrongs that result, neither the common law nor the courts appear any longer to be adequate bulwarks and sources of remedy. Indeed, so great has become the threat of the administrative juggernaut that in the English-speaking world consideration is being given to adoption of arrangements resembling the office of Ombudsman established in Nordic countries to guard the citizen against the bureaucrat. For like reason in some of the emerging Asian nations (e.g., Ceylon, India, Malaya, Pakistan) the type of control incorporated in the French Conseil d'Etat is commanding attention, in part on the ground that it is more effective and universally applicable than the institution of Ombudsman. ${ }^{35}$

It may be noted parenthetically that the ultimate problem is that of achieving a measure of humane judicial control over the administrative process, a process that computer use might render even more mechanistic and rational than it is already. This can be accomplished more fully than at present by increasing recourse to both judicialization of the administrative process and expansion of the scope of judicial review over administrative action. Given such increase, the role of the common law tradition, always much better understood by the judiciary than by the bureaucracy, will be enlarged, and administrative judgment will be better articulated with the general standards of freedom and liberty implicit in that tradition. A byproduct will be erection of a more powerful barrier to the misuse of computer and related methóds. ${ }^{36}$

It is conducive to individual and aggregate welfare in a modern "welfare" or social-service state (even as in a less function-laden state) that the definition and administration of justice be kept as flexible as possible and that individuals remain as free from constraint by agencies of the state as is compatible with the objectives specified and sought by the legislature (which presumably reflects the welfare function of the underlying population). The dangers arising from conceptual rigidity, bias in analysis and interpretation, and other possible concomitants of the use of computers in the definition and administration of justice tend to be very great in a "welfare" state. In a dynamic society, furthermore, a conceptual structure,

s Petro, The Growing Threat of Antitrust, Fortune, Nov. 1962, p. x28; also, unsigned, Signposts of the Supreme Court's Aititude Toward Business, id. at I3I. See also Donald Dewey, Monopoly in ECONOMICS AND LAw 309-Io (I959).

${ }^{35}$ See, e.g., Rowat, An Ombudsman Scheme for Canada, 28 Can. J. Econ. \& Pol. Scr. 543 (I962). On Pakistani and Indian views respecting the need of the French type of bureaucratic control, see Braibanti, Public Bureauctacy and Judiciary in Pakistan, in Joseph LaPalombara (ED.), Bureaucracy in Political Development (I963), and Government of Indi, Ministry of Law, Fourteenth Report of the LAw Commission of Indi-Reform of Judicial Administration $671-98$ (r958).

${ }^{30}$ This paragraph reflects my conversations with my colleague, Professor Ralph Braibanti. On the common law and the administrative process, see James M. Landis, The Administrative Process (r938). 
if relatively rigid (as is that summarized on the first line in table one), would become increasingly badly geared to changing reality as time passed.

The dangers noted are certain to be accentuated, moreover, in the event that a powerful and unchecked role is played by administrative agencies which enjoy a large amount of autonomy and discretion and a considerable though not precisely defined amount of freedom from restrictive judicial review and rights-guarding action on the part of other complaint-handling agencies. At the same time the individual, together with his counsel, may find himself handicapped if he lacks inexpensive access to computers and similar instruments being utilized by the state in building a case against him. The typical defendant will then find himself in a position somewhat similar to that of Marx's proletarian who, lacking tools or the assistance of public capital, was more or less at the mercy of the owner of capital whose position was somewhat analogous to that of the modern state in a computerridden world from which the rhetorical supports of "justice" have been largely removed.

\section{Concrusion}

In this essay I have shown how and why biases may be introduced along with the use of computers and similar instruments in the definition and administration of justice. Such bias is not always and necessarily a concomitant of the use of computers and similar instruments, but it can easily become one unless effective safeguards are set up. In many instances, moreover, computer use will necessarily introduce bias because the subject matter is not adaptable to such use. Furthermore, these instances are likely to increase in number as the relatively static conceptual structure adapted to computer programming becomes increasingly less reflective of a changing, dynamic reality and therefore misdirects and distorts inquiry. In so far as this happens, justice will suffer and the augmentation of aggregate welfare will be retarded. My main arguments were advanced in sections one and two.

In section one it was contended that aggregate welfare tends to be relatively great when three conditions are present: when constraints upon decision-makers remain as limited as possible; when decision-makers are free to change their positions as circumstances change; and when the conceptual structures underlying goal-directed behavior remain flexible. The value of freedom from constraint beyond the minimum necessary to maximize some specified welfare function was defined in instrumental terms. It was so defined because in many societies, such as our own, we achieve justice and welfare in very large measure through the adjustment of individuals to one another as well as to changes in the external environment. In consequence, any unnecessary interference by the state with the adjustment and negotiation processes involved, or with the freedom that makes these processes possible, is adverse both to the objectives of "justice" and the maximization of welfare. 
In section two it was shown that, under certain circumstances, increase in conceptual rigidity and bias is a highly probable even when not a necessary sequel to the use of computers and similar instruments in the definition and administration of justice. This may come about if computer-oriented concepts and information are imperfectly adjusted to those portions of the world of reality in respect of which "justice" is sought. Then administrators, judges, and so on, must choose one of two courses; they must accommodate their use of computers to these limitations; or they must redefine "justice," together with the information required in its administration, in such wise as to increase greatly the role of computers. Given the latter choice, there results greater rigidity of the conceptual structure and increasing subordination of the requirements of justice to the requirements of programming. It does not follow, of course, that the latter choice would be made. Pressure for making it might, however, flow from the clogged state of the courts and other facilities of justice and from the great economy of time that use of computers seemingly might make possible. It was also shown that reliance upon computer and similar mechanical instruments readily served in other ways besides rigidifying the conceptual structure to introduce bias and distortion in the definition and the administration of justice. Attention was not given to the possibility that man would develop computing machinery capable both of receiving much more refined concepts in its input and of reflecting these in its output; for then prohibitively large machines would be required to reflect as much conceptual differentiation as optimal administration of justice calls for.

In the third section it was shown that the role of the state in society was steadily increasing and that this increase in turn had given rise to increase in the role of administrative agencies which are largely autonomous and markedly free of judicial review. Under these circumstances, given the clogged state of many of these administrative agencies and the economies in time that computer use-might make possible, the agencies in question were likely to find themselves under pressure to orient their procedures to computer use, a task made easier in proportion as these agencies remained free of judicial review and other restraints. The burden of the argument advanced in the third section thus was that dangers from the misuse of computers depend significantly upon the kind of society and state making use of computers in the definition and administration of justice, and that the modern state is particularly prone to such misuse.

It was also suggested in section three, though the argument was not developed, that the frequently present disparity between the individual defendant and the prosecuting state would be greatly enlarged by the introduction of computers, for the state would probably be well-equipped with computers, and so on, whereas the defendant and his counsel were likely to lack ready and economic access to such equipment. Then the probability of bias against the less well-to-de defendant would be enhanced. This possible source of difficulty may, of course, prove more avertable or remediable than others to which attention was drawn in the third section. 
If the arguments we have advanced are valid, great care must be exercised to avert the biases, the distortions, and the probable miscarriages of justice to which we have drawn attention. If computers and other instruments are to be used, every precaution must be taken lest the mechanical servant become master, and a tyrannical one at that. For then this new, supposed instrument of justice would merely have become another Sorcerer's Apprentice. ${ }^{37}$

${ }^{87}$ Arguments underlying F. B. Wiener's findings that reliance upon machines "rather than on his own powers of reasoning and advocacy" blunts a lawyer's "professional techniques" are in keeping with some of those put forward in this essay. See Wiener, Decision Prediction by Computers: Nonsense Cubedand Worse, 48 A.B.A.J. 1023 (1962). 